\title{
Correlation between urinary 2-methoxy acetic acid and exposure of 2-methoxy ethanol
}

\author{
Tung-Sheng Shih, Saou-Hsing Liou, Cheng-Yao Chen, Jui-Shu Chou
}

Institute of

Occupational Safety and Health, Council of Labor Affairs, 4th Floor, 132 Min-Sheng East Road, Section 3, Taipei, Taiwan, Republic of China T-S Shih C-Y Chen J-S Chou

Department of Public Health, National Defense Medical Center, Taipei, Taiwan, Republic of China S-H Liou

Institute of Occupational Safety and Health, Council of Labor Affairs, Executive Yuan, Republic of China T-S Shih

Correspondence to: Dr Tung-Sheng Shih, Division of Method Development and Analysis, 4th Floor, 132 Min-Sheng East Road, Section 3, Taipei, Taiwan, Republic of China Telephone 0088628770 1559; fax 0088625451048 or 1049; email

stone@mail.cla.gov.tw

Accepted 14 June 1999

\begin{abstract}
Objectives-To examine the correlation between airborne 2-methoxy ethanol (ME) exposures and the urinary 2-methoxy acetic acid (MAA) and to recommend a biological exposure index (BEI) for ME.

Methods-8 Hour time weighted average (TWA) personal breathing zone samples and urine samples before and after the shift were collected from Monday to Saturday for 27 workers exposed to $\mathrm{ME}$ and on Friday for 30 control workers.

Results-No correlation was found between airborne exposure to $M E$ and urinary MAA for nine special operation workers due to the use of personal protective equipment. For 18 regular operation workers, a significant correlation $(r=0.702$, $p=0.001$ ) was found between urinary MAA (mg/g creatinine) on Friday at the end of the shift and the weekly mean exposures of $M E$ in a 5 day working week. The proposed BEI, which corresponds to exposure for 5 days and 8 hours a day to $5 \mathrm{ppm}$, extrapolated from the regression equation is 40 mg MAA/g creatinine. A significant correlation was also found between the weekly increase of urinary MAA (Friday after the shift minus Monday before the shift) and the weekly mean exposures of $\mathrm{ME}$ $(r=0.741)$. The recommended value of the weekly increase of urinary MAA for 5 days repeated exposures of $5 \mathrm{ppm} \mathrm{ME}$ is 20 $\mathrm{mg} / \mathrm{g}$ creatinine. No urinary MAA was detected in workers in the non-exposed control group.
\end{abstract}

Conclusions-The Friday urinary MAA after the shift or the weekly increase of urinary MAA is a specific and a good biomarker of weekly exposure to ME.

(Occup Environ Med 1999;56:674-678)

Keywords: 2-methoxy acetic acid; 2-methoxy ethanol; biological monitoring

The solvent 2-methoxy ethanol (ME) is a widely used solvent in industries - such as the production of 2-methoxy acetate, plasticiser of $35 \mathrm{~mm}$ film, insulation for high voltage wires, high flash coatings, component of the photoresistant material used in photolithography of semiconductor circuit designs - in addition to being used in coating or lamination resins of circuit boards. Substantial quantities are used as de-icing additives in military jet fuel. ${ }^{12}$ The annual consumption of $\mathrm{ME}$ is over 3000 tonnes in Taiwan. With the rapid growth of the semiconductor manufacturing industry in
Asia, the quantitative exposure assessment of $\mathrm{ME}$ becomes increasingly important.

Animal and human studies have shown that ME can cause adverse reproductive, developmental, and haematological effects through inhalation, dermal absorption, and ingestion. ${ }^{2-7}$ Metabolic studies showed that ME is metabolised to 2-methoxy acetic acid (MAA) through alcohol dehydrogenase and aldehyde dehydrogenase. $^{8-10}$ In humans, the total amount of MAA excreted in the urine accounts for about $85.5 \%$ of the inhaled $\mathrm{ME} .{ }^{10}$ In vitro studies showed that ME itself evokes no toxic responses either in Sertoli cell culture ${ }^{9}$ or in rat whole embryo culture, whereas MAA does. ${ }^{11}$ In vivo studies showed that equivalent doses of $\mathrm{ME}$ and its corresponding major metabolite, MAA, are equally effective in causing adverse effects. ${ }^{912}$ MAA, therefore, was suggested as the proximate toxicant of ME exposure. ${ }^{811} 1415$

The United States National Institute for Occupational Safety and Health (NIOSH) suggests that urinary MAA is a specific and good biomarker of exposure to ME. ${ }^{1}$ Until now, however, urinary MAA has not been detected in humans except for two human subject studies in the laboratory. ${ }^{10}{ }^{16}$ The American Conference for Governmental Industrial Hygienists (ACGIH) biological exposure indices (BEIs) committee, has put ME in the adopted list of determinants of biological exposure and has tried for several years to recommend a BEI value for ME based on the committee's review of publications; however, a specific BEI could not be decided due to insufficient human data. ${ }^{17}$

The main purposes of this paper are to examine the correlation between the airborne exposures to $\mathrm{ME}$ and the internal doses (urinary MAA) and to recommend a BEI for ME.

\section{Materials and methods}

MANUFACTURING PROCESS

Two types of operations are basically performed in this study in a manufacturing plant of semiconductor copper laminate circuit boards. The regular operations include unwinding, splicing, accumulation, dipping, oven heating, edge trimming, rewinding, and sheeting operations. Workers were exposed to $\mathrm{ME}$ mainly in dipping and oven heating operations. The special operations include raw material mixing, charging, machine cleaning, and maintenance work.

\section{SUBJECTS}

A total of 27 workers, 18 in regular operations and nine in special operations, participated in this study. In special operations, two workers 
handled the raw material mixing, charging, and discharging, and seven workers were in charge of the cleaning and maintenance of the coating machine. Twenty workers in the administrative department and 10 workers in the heat press operations of the same plant were chosen as the control groups. All workers were in fixed work shifts and were asked not to have alcohol, medication, and other exposures of organic solvents (such as painting at home) during this study. Informed consent was given by all workers who participated in this study.

\section{CHEMICALS USED IN THE MANUFACTURING} PROCESS

The main raw materials used in this plant include epoxy and phenolic resins, hardener (dicyanamide), catalyst (2-methylimidazole), antimony oxide $\left(\mathrm{Sb}_{2} \mathrm{O}_{3}\right)$, aluminum oxide, silica dioxide, $\mathrm{ME}$, acetone, titanium oxide, and pigments. Acetone and ME are the only two volatile chemicals used in the workplace. The coating glue contains $70 \%$ of $\mathrm{ME}$, and $30 \%$ of acetone. The qualitative confirmation of $\mathrm{ME}$ in raw materials were reconfirmed by gas chromatography-mass spectrometry (GC-MS G1,800A, GCD, Hewlett Packard, Palo Alto, CA, USA).

ENGINEERING CONTROL AND PERSONAL

PROTECTIVE EQUIPMENT

All coating machinery was installed in enclosed rooms with aluminum sliding doors. Incinerators were installed above each coating machine to burn off the waste solvent exhaust vapours. Occasionally, workers were exposed to high concentrations of $\mathrm{ME}$ when the doors of the coating rooms were not closed. For the rest of the time, workers stayed in air conditioned control rooms. For the duration of this study, workers in regular operations agreed to wear protective rubber gloves to avoid contact with the glue that contained ME. All exposed workers wore short sleeved work clothes. Exposure to $\mathrm{ME}$ in regular operations mainly came through inhalation and skin absorption of $\mathrm{ME}$ vapour.

Workers in the special operations were exposed to high concentrations of $\mathrm{ME}$ when they went into the enclosed rooms for machine cleaning, trouble shooting, maintenance, and machine fixing. Raw materials were mixed, charged, and discharged in a separated workplace without ventilation. Workers were exposed to high concentrations of $\mathrm{ME}$ when the raw materials were charged, mixed in the reactors, and when manholes of the reactors were opened to charge the solid raw materials. Most workers in the special operations wore respirators and rubber gloves, but a few of them removed the respirators or gloves for a very short time during exposures. Therefore, the exposures in special operations might have come through inhalation, the inadvertent contact of liquid $\mathrm{ME}$ with the hands, and whole body skin absorption of ME vapour. The exposure time was short in the coating department and raw material handling area. The relative humidity in the workplaces was around $80 \%$ $85 \%$. The temperature in the control rooms and the enclosed rooms for dipping or oven heating areas were $25-27^{\circ} \mathrm{C}$ and $30-33^{\circ} \mathrm{C}$, respectively.

EXPOSURE MONITORING

Eight hour time weighted average (TWA) personal breathing zone samples were collected for 27 exposed workers from Monday to Saturday and for 30 workers in the control group on Friday. The Taiwan Institute of Occupational Safety and Health (IOSH) standard procedure 1215 was used to sample, measure, and analyse the airborne ME concentrations in this study. ${ }^{18}$ This standard was fully validated with a dynamic standard gas generation system and also by three accredited industrial hygiene laboratories in Taiwan.

Personal breathing zone samples were collected by drawing air through standard size coconut shell charcoal tubes (SKC 226-01, batch No 120, PA, USA), with Gilian constant low flow personal pumps (Model LFS-114, NJ, USA), then desorbed in $1 \mathrm{ml}$ of mixed solvent of 95:5 (v/v) dichloromethane $(99.7 \%, \mathrm{E}$ Merck, Darmstadt, Germany) and methanol (99.7\%, E Merck). After 40 minutes shaking, the desorbed $\mathrm{ME}$ was analysed by a gas chromatography (GC) (Hewlett-Packard 5890 Series II, CA, USA) equipped with a HP 7673A autosampler and a flame ionisation detector.

The overall accuracy (bias plus twice the precision) was $\pm 9.5 \%$, the reliable measurement limit was $4 \mathrm{ng}$. The sampling flow rate was calibrated before and after each sample. All air samples were analysed by an accredited industrial hygiene laboratory in Taiwan within 1 week of sampling (samples were stored at $-20^{\circ} \mathrm{C}$ ).

\section{BIOLOGICAL MONITORING}

Urine samples before and after the shift were collected from 27 exposed workers for 6 days, and urine samples were collected after the shift from 30 workers in the control group on Friday. Urinary MAA was measured by a modified method previously reported by Sakai et al. ${ }^{19}$ This method was fully validated by IOSH and also by two reference laboratories before it was adopted in this study. ${ }^{20}$

An internal standard of $0.1 \mathrm{ml}$ butoxy acetic acid (BAA, 99.0\%, E Merck, Darmstadt, Germany) was added to $1 \mathrm{ml}$ urine, which was acidified with $0.1 \mathrm{ml}$ concentrated hydrogen chloride. The MAA was then extracted with 1 $\mathrm{ml}$ of the mixture of 2:1 (v:v) dichloro-methane (99.7\%, E Merck) and isopropyl alcohol (99.7\%, E Merck) for 10 minutes. After centrifuging, $0.5 \mathrm{ml}$ of the lower layer was transferred to a $1.5 \mathrm{ml}$ vial, and $25 \mu \mathrm{l}$ of a solution of trimethylsilyldiazomethane (TMSD, 2.0 M solution in hexane, Aldrich, WI, USA) was added. The esterified acid was analysed by a gas chromatogram equipped with an HP 7673A autosampler and a flame ionisation detector.

The MAA concentration range of the standard curve was $3.5-200 \mu \mathrm{g} / \mathrm{ml}$. The limit of measurement (mean plus 10 SDs of the blank) was $0.136 \mu \mathrm{g} / \mathrm{ml}$. Urinary creatinine was analysed by the Jaffe method for concentration correction. The results of urine samples were expressed as mg MAA/g creatinine. All urine samples were analysed by one reference 
The 6 day time weighted average (TWA) exposures of 2-methoxy ethanol (ME) for 18 regular operation workers and nine special operation workers

\begin{tabular}{llll}
\hline $\begin{array}{l}\text { Regular } \\
\text { operation } \\
\text { workers }\end{array}$ & $\begin{array}{l}\text { Weekly exposures } \\
\text { of } M E \text { mean } \\
(S D) \text { ppm }\end{array}$ & $\begin{array}{l}\text { Special } \\
\text { operation } \\
\text { workers }\end{array}$ & $\begin{array}{l}\text { Weekly exposures } \\
\text { of } M E \text { mean } \\
(S D) \text { ppm }\end{array}$ \\
\hline 1 & $3.91(2.66)$ & 1 & $32.90(61.97)$ \\
2 & $4.46(2.38)$ & 2 & $23.61(53.16)$ \\
3 & $1.62(1.50)$ & 3 & $25.22(60.13)$ \\
4 & $0.97(0.58)$ & 4 & $35.53(65.97)$ \\
5 & $0.72(0.73)$ & 5 & $38.40(62.33)$ \\
6 & $7.46(5.62)$ & 6 & $37.26(63.97)$ \\
7 & $5.45(5.44)$ & 7 & $48.27(70.43)$ \\
8 & $9.73(4.36)$ & 8 & $267.6(351.4)$ \\
9 & $3.39(1.83)$ & 9 & \\
10 & $4.32(2.44)$ & & \\
11 & $8.86(4.98)$ & & \\
12 & $4.57(5.92)$ & & \\
13 & $1.01(0.54)$ & & \\
14 & $6.18(10.2)$ & & \\
15 & $3.97(2.82)$ & & \\
16 & $3.91(2.19)$ & & \\
17 & $6.01(2.92)$ & & \\
18 & $3.78(3.12)$ & & \\
\end{tabular}

The daily mean (SD) exposures of ME for 18 regular operation workers from Monday to Saturday were 3.26 (4.65), 5.76 (4.50), 4.64 (4.31), 5.31 (4.10), 5.03 (3.70), and $2.61(2.65)$ $\mathrm{ppm}$, respectively, with a weekly mean (SD) exposure level of 4.46 (2.56) ppm.

The daily mean (SD) exposures of ME for 9 special operation workers from Monday to Saturday were 279.2 (258.0), 152.8 (303.9), 25.60 (26.35), 10.26 (19.06), 17.38 (27.29), and 4.43 (4.76) ppm, respectively, with a weekly mean (SD) exposure level of 81.61 (111.7) ppm.

laboratory in Taiwan within 2 weeks of sampling (samples were stored at $-80^{\circ} \mathrm{C}$ ). Urinary MAA is stable for at least 5 months, and for three freeze-thaw cycles from $-20^{\circ} \mathrm{C} .^{20}$ Pooled urine samples from 12 unexposed people were used as a matrix blank and were checked for background interference.

\section{Results}

ENVIRONMENTAL MONITORING

The GC and gas chromatography/mass spectrometry (GC/MS) analysis of bulk samples and randomly selected air samples confirmed that $\mathrm{ME}$ and acetone were the only two volatile chemicals in the workplace.

A total of 1498 hour TWA personal breathing zone samples were collected from 27 exposed workers. The daily mean (SD) exposures of $\mathrm{ME}$ for 18 regular operation workers from Monday to Saturday were 3.26 (4.65), 5.76 (4.50), 4.64 (4.31), 5.31 (4.10), 5.03 (3.70), and 2.61 (2.65) ppm, respectively. The weekly mean (SD) exposure was 4.46 (2.56) ppm (table).

For the nine special operation workers, however, the exposures were much higher. The daily mean (SD) exposures of ME from Monday to Saturday were 279.2 (258.0), 152.8 (303.9), 25.60 (26.35), 10.26 (19.06), 17.38 (27.29), and 4.43 (4.76) ppm, respectively. The weekly mean (SD) exposure was 81.61

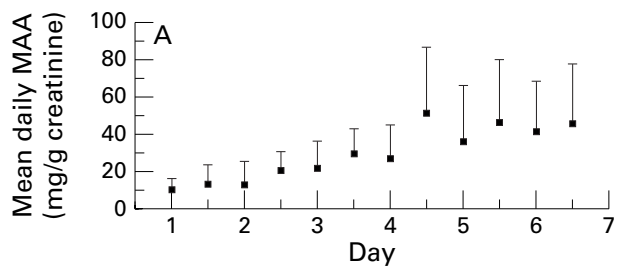

(111.7) ppm (table). It was also noticed that peak exposures happened mainly in the first and the second day of the week. The mean (SD) peak exposures during the mixing of raw materials (on Monday and Tuesday) and in cleaning the coating machine (on Monday) were 690.7 (187.6) and 154.5 (15.4) ppm, respectively. When these peak exposures were excluded, the mean (SD) exposures of the workers who did these two operations dropped dramatically to 29.96 (28.60) and 8.87 (15.81) ppm, respectively.

No background exposures were detected in the control group workers, except for three heat press workers whose working position was closely adjacent to the coating department. The exposures of those workers were very low (the 8 hour TWA ME exposures were in the range of $0.2-0.3 \mathrm{ppm}$ ).

The recoveries of 20 sets of blind field samples (spiked quality control samples mixed with field samples) were in the range of $94 \%$ to $108 \%$. The mean (SD) recoveries of proficiency analytical testing samples from three different accredited laboratories were 97.19 (3.36)\%, $98.52(2.10) \%$, and $97.72(2.39) \%$, respectively. These results validate the reliability of the exposure monitoring data obtained in this study.

\section{BIOLOGICAL MONITORING}

Urinary MAA was confirmed by GC-MS. A total of 309 spot urine samples were collected from 27 exposed workers. Five urine samples were not included in the data analyses either due to the extreme concentrations of urinary creatinine $(<0.3 \mathrm{~g} / 1$ or $>3 \mathrm{~g} / \mathrm{l})$ or low urinary MAA concentrations $(<3.5 \mu \mathrm{g} / \mathrm{ml}$, the lowest concentration of the standard curve).

The daily mean (SD) urinary MAA of 18 regular operation workers showed a clear increase from 10.57 (5.85) $\mathrm{mg} / \mathrm{g}$ creatinine on Monday before the shift to $46.46(33.49) \mathrm{mg} / \mathrm{g}$ creatinine on Friday after the shift (figure $1 \mathrm{~A}$ ) even though their daily mean airborne exposures were consistent and close to the current 5 ppm permissible exposure limit (PEL).

It was surprising to notice that the daily mean urinary MAA of the highly exposed workers in special operations was even lower than that in regular operations. The daily mean (SD) urinary MAA of workers in special operations also increased clearly from 10.17 (9.00) $\mathrm{mg} / \mathrm{g}$ creatinine on Monday before the shift to 29.55 (17.72) $\mathrm{mg} / \mathrm{g}$ creatinine on Friday after the shift (fig $1 \mathrm{~B}$ ).

No background urinary MAA was detected in control workers except for the three heat press workers already mentioned. The urinary

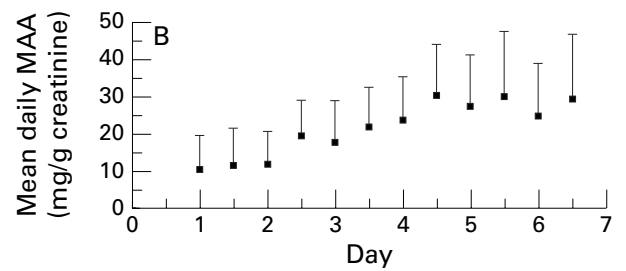

Figure 1 (A) Mean daily urinary 2-methoxy acetic acid (MAA, $\mathrm{mg} / \mathrm{g}$ creatinine) of 18 workers in regular operations from Monday to Saturday. (B) Mean daily urinary MAA of 9 workers in special operations from Monday to Saturday. Data are means (SDs). 


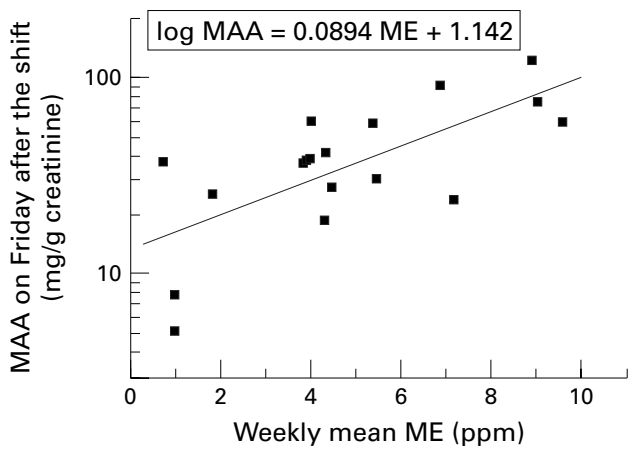

Figure 2 Correlation between the urinary $M A A$ on Friday after the shift and the mean weekly TWA exposures to $M E$.

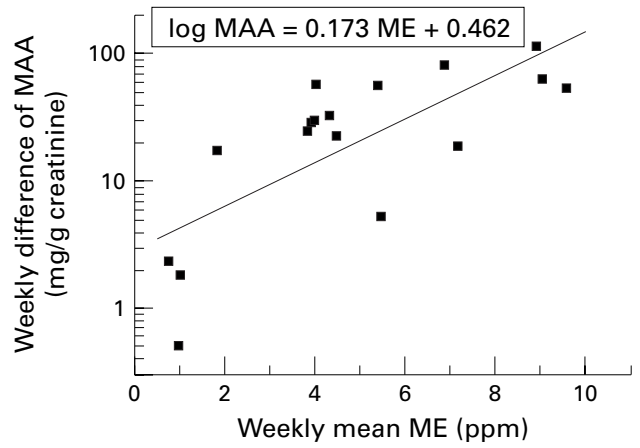

Figure 3 Correlation between the weekly increase of urinary MAA (Friday after the shift to Monday before the shift) and the mean weekly TWA exposures to ME.

MAA concentrations $(0.4-0.5 \mu \mathrm{g} / \mathrm{ml})$ of these workers were well below the lowest concentration of the calibration curve $(3.5 \mu \mathrm{g} / \mathrm{ml})$.

A total of 64 sets of triplicate analysis of urinary concentrations of MAA showed a pooled coefficient of variation of $3.07 \% \quad(0.30 \%-$ $7.76 \%$ ) over the concentration range of 6.27 $238.77 \mu \mathrm{g} / \mathrm{ml}$. No interfering chemicals were found in GC and GC-MS results of randomly selected urine samples. The recoveries of 20 sets of blind quality control samples were from $93.23 \%$ to $113.75 \%$. These results validate the reliability of the biological data.

CORRELATION BETWEEN THE AIRBORNE EXPOSURES TO ME AND THE INTERNAL DOSES No correlation was found $(p>0.3)$ between the weekly mean exposures of $\mathrm{ME}$ and the urinary MAA on Friday after the shift for all the 27 exposed workers.

When the workers in special operations were excluded, a significant correlation was then found between the urinary MAA on Friday after the shift and the weekly mean exposures to $\mathrm{ME}$ (log $\mathrm{MAA} \quad(\mathrm{mg} / \mathrm{g}$ creatinine) $=1.142+0.089 \times \mathrm{ME}(\mathrm{ppm}), \mathrm{p}=0.001, r=0.702$ (fig 2)). The correlation coefficients were reduced from 0.702 to 0.601 when urinary MAA concentrations were not corrected by creatinine.

A similar correlation was found between the weekly mean exposures to $\mathrm{ME}$ and the weekly increase of urinary MAA (Friday after the shift minus Monday before the shift) (log MAA $(\mathrm{mg} / \mathrm{g}$ creatinine $)=0.173 \times \mathrm{ME}(\mathrm{ppm})+0.462$, $\mathrm{p}=0.0007, \mathrm{r}=0.741$ for a 5 day working week (fig 3)).

\section{Discussion}

To the best of our knowledge, this is so far the only study that examines the correlation between airborne exposures to $\mathrm{ME}$ and the internal dose (urinary MAA) and the recommended BEI of ME in the literature.

The NIOSH has recommended that if end of shift urinary MAA exceeds $0.8 \mathrm{mg} / \mathrm{g}$ creatinine, then there is evidence of occupational exposure to $\mathrm{ME} .^{1}$ This value was extrapolated from Groeseneken's 4 hour human experimental exposure by inhalation ${ }^{10}$ for $4-50$ minute periods at rest to $5.1 \mathrm{ppm}$, to an 8 hour exposure by inhalation to $0.1 \mathrm{ppm}$ at 60 watts of exercise. Although $5 \mathrm{ppm}$ is currently the most popular PEL for ME in the world, NIOSH has not recommended a BEI corresponding to this concentration.

Several points need to be discussed for the above recommendation. Firstly, the recommended value was based on exposures through inhalation only. A recent human subject study showed that the dermal absorption of vaporous ME could cause an even higher uptake than exposure to the same dose through inhalation. ${ }^{16}$ The absorption of $\mathrm{ME}$ vapour through the skin was unavoidable in the workplaces. Secondly, the half life of urinary MAA in humans was 77.1 hours. ${ }^{10}$ Our data in this field study have shown a clear accumulation of urinary MAA in workers repeated exposed daily. Values based only on single exposure through inhalation would result in an underestimated internal dose. In this study, correlations between the weekly mean exposures of $\mathrm{ME}$ and the urinary MAA on Friday after the shift and the weekly increase of urinary MAA were examined. The recommended BEI proposed in this way not only considered both the inhalation exposures and the absorption of vapour through the skin, but also accounted for the accumulation of internal dose in repeated daily exposures.

In this study, a significant correlation between the weekly mean exposures of $\mathrm{ME}$ and the Friday urinary MAA after the shift was found in workers in regular operations. This was consistent with the suggestions of the United States ACGIH. ${ }^{17}$ The recommended BEI of urinary MAA corresponding to exposures from 5 consecutive days full shifts to a concentration of ME in air of $5 \mathrm{ppm}$ extrapolated from the linear regression was $40 \mathrm{mg}(0.45$ $\mathrm{mmol}) \mathrm{MAA} / \mathrm{g}$ creatinine. The correction of creatinine provided a better correlation. Veulemans et al in their field study of 2-ethoxy ethanol (EE) have proposed a BEI of $150 \mathrm{mg}$ (1.47 mmol) 2-ethoxy acetic acid (EAA)/g creatinine for exposures of EE at 5 ppm. ${ }^{21}$ The ACGIH recommended BEI for $\mathrm{EE}$ is $100 \mathrm{mg}(0.98$ mmol) EAA/g creatinine. ${ }^{17}$ A more stringent recommended $\mathrm{BEI}$ for $\mathrm{ME}$ obtained from this study is also reasonable due to the higher toxicity of ME. In this study, the daily exposures during regular operations were stable and close to the current PEL ( $5 \mathrm{ppm}$ ) during the working week. Workers basically only performed light physical work with short sleeved working clothes and no direct contact of liquid ME. The exposures came mainly from inhalation and 
absorption of vapour through the skin. Both air and biological samples were randomly reconfirmed by GC/MS, which is one of the most specific and powerful methods for analyses of organic compounds. The good quality control programme and high recoveries of quality control and blind samples confirmed that both the environmental monitoring and biological monitoring data in this study were valid.

As the half life of urinary MAA in humans is 77.1 hours, ${ }^{10}$ high previous exposures may result in a considerable increase in the baseline urinary MAA during the next week. It is therefore recommended that the weekly increase of urinary MAA between the end of the shift at the end of the working week and before the shift on Monday may be an alternative biomarker to reflect the weekly exposures of ME. The recommended value of this weekly increase of urinary MAA (corresponding to 5 continuous days of exposure to $5 \mathrm{ppm} \mathrm{ME}$ ) extrapolated from our linear regression (fig 3) is $20 \mathrm{mg} / \mathrm{g}$ creatinine.

For special operations, the correlation between external exposures and internal doses was much more complicated and difficult to establish than that in regular operations. For most of the workers in special operations, the external exposures were extremely high, but the actual uptake was low mainly due to the proper use of butyl rubber gloves and charcoal cartridge respirators. Therefore, the workers in special operations were well protected with effective personal protective equipment. The Council of Labor Affairs also had the authority to make the employer and employees cooperate and follow the good working practises and safety guidelines and stay for only a short time in areas of high exposure during this study. On the other hand, the heavy work carried out in loading could cause more sweat to wet the body surface and working clothes (ME is highly water soluble and permeable to the skin). Short periods of inadvertent skin contact with glue (containing $\mathrm{ME}$ ) was noted. Whole body skin absorption of $M E$ vapour was also difficult to avoid. All these factors made the prediction of internal dose in workers in special operations very difficult. In situations like this, the traditional environmental monitoring might provide false information on the actual exposure to ME. The internal dose, on the other hand, can provide better information on the actual uptake and reflect the concentrations in the target sites.

It was noticed that the non-peak exposures in workers doing special operations were much lower, but the urinary MAA was significantly higher than that in peak exposures. This probably could be explained by the proper use of personal protective equipment in peak exposures (Monday) and the considerable accumulation of internal dose during the non-peak exposures (Tuesday to Saturday).

No background urinary MAA was detected in non-exposed workers in the control group, consistent with other reports. ${ }^{12}$ Only low urinary MAA $(0.4-0.5 \mu \mathrm{g} / \mathrm{ml})$ was detected for three workers with low background exposures to $\mathrm{ME}(0.2-0.3 \mathrm{ppm})$. This further validated the specificity of urinary MAA as the biomarker of exposure to $\mathrm{ME}$.
It is therefore concluded that urinary MAA is a specific and a good biomarker of the exposures to ME. The recommended BEI obtained in this study was $40 \mathrm{mg} \mathrm{MAA} / \mathrm{g}$ for urinary MAA on Friday after the shift that corresponds to exposures from 5 consecutive days full shifts to a concentration of $\mathrm{ME}$ air of $5 \mathrm{ppm}$ creatinine. The recommended value of the weekly increase of urinary MAA corresponding to 5 consecutive days full shifts to a concentration of ME air of $5 \mathrm{ppm}$ creatinine was $20 \mathrm{mg} / \mathrm{g}$ creatinine.

We are grateful to Dr On-Chih Hsieh and Dr Guo-Dong Liow for their assistance in the collection of urine samples, and $\mathrm{Dr}$ Jing-Shiang Hwang for the statistical analyses of data. This work was supported by the Institute of Occupational Safety and Health, Council of Labor Affairs, Executive Yuan, Taiwan, Republic of China (IOSH grant 85-A304).

1 National Institute of Occupational Safety and Health. Criteria for a recommended standard: occupational exposure to ethylene glycol monomethyl ether, ethylene glycol monoethyl ether, and their acetates. Washington, DC: NIOSH, 1991. (Publ No their acetates

2 Occupational Safety and Health Administration. Occupational exposure to 2-methoxy ethanol, 2-ethoxy ethanol, and their acetates (glycol ethers); proposed rule. Federal Register. Washington, DC: OSHA, 1993. (29CFR, Vol 58, No 54, Docket No H-044.)

3 Nagano K, Nakayama E, Oobayashi H, et al. Experimental studies on toxicity of ethylene glycol monomethyl ether in Japan. Environ Health Perspect 1984;57:75-84.

4 Larese F, Fiorito A, Zotti RD. The possible haematological effects of glycol monomethyl ether in a frame factory. $\mathrm{Br} \mathcal{F}$ Ind Med 1992;49:131-3.

5 Wickramaratne GA. The teratogenic potential and doseresponse of dermally administered ethylene glycol monomethyl ether estimated in rats with the Chernoff-Kavlock methyl ether estimated in rats with

assay. $\mathcal{F}$ Appl Toxicol 1986;6:165-6.
6 Welch LS, Schrader SM, Turner TW, et al. Effects of exposure to ethylene glycol ethers on shipyard painters: II. Male sure to ethylene glycol ethers on shipyard paint
reproduction. Am F Ind Med 1988;14:509-26.

7 Welch LS, Cullen MR. Effects of exposure to ethylene glycol thers on shipyard painters: III. Hematological effects. Am Ind Med 1988;14:527-36.

8 Miller RR, Hermann EA, Langvardt PW, et al. Comparative metabolism and disposition of ethylene glycol monomethyl ther and propylene glycol monomethyl ether in male rats. Toxicol Appl Pharmacol 1983;67:229-37.

9 Moss EJ, Thomas LV, Cook MW, et al. The role of metabolism in 2-methoxy ethanol induced testicular toxicity. Toxicol Appl Pharmacol 1985;79:480-9.

10 Groeseneken D, Veulemas H, Masschelein R, et al. Experimental human exposure to ethylene glycol monomethyl ether. Int Arch Occup Environ Health 1989;61:243-7.

11 Yonemoto J, Brown NA, Webb M. Effects of dimethoxyl phthalate, monomethoxyethyl phthalate, 2-methoxyethanol and methoxyacetic acid on post-implanatation rat embryos in culture. Toxicol Lett 1984;21:97-102.

12 Miller RR, Carreon RE, Young JT, et al. Toxicity of methoxyacetic acid in rats. Fundam Appl Toxicol 1982;2: $158-60$.

13 Sleet RB, Greene JA, Welsch F. The relationship of embryotoxicity to disposition of 2-methoxyethanol in mice. Toxicol Appl Pharmacol 1988;93:195-207.

14 Brown NA, Holt D, Webb M. The teratogenicity of methoxyacetic acid in the rat. Toxicol Lett 1984;22:93-100.

15 Ritter EJ, Scott WJ Jr, Randall JL, et al. Teratogenicity of dimethoxyethyl phthalate and its metabolites methoxy ethanol and methoxyacetic acid in the rat. Teratology 1985 ;
32:25-31.

6 Kezic S, Mahieu K, Monster A, et al. Dermal absorption of vaporous and liquid 2-methoxyethanol and
2-ethoxyethanol in volunteers. Occup Environ Med 1997;54: 2-ethoxyeth

17 American Conference of Governmental Industrial Hygienists. TLVs threshold limit values for chemical substances and physical agents and biological indices (BEIs). Cincinnati, $\mathrm{OH}$ : ACGIH; 1998:97-101.

18 Institute of Occupational Safety and Health. Recommended sampling and analytical methods for 2-methoxy ethanol (method 1215). Taipei, Taiwan, Republic of China: IOSH, 1992 .

19 Skai T, Araki T, Masuyama Y. Determination of urinary alkoxy acetic acids by a rapid and simple method for biological monitoring of workers exposed to glycol ethers and their acetates. Int Arch Occup Environ Health 1993;64:495-8.

20 Chang MJ, Shih TS, Chou JS. Recommended biological monitoring method to measure urinary alkoxy acetic acids. monitoring method to measure urinary alkoxy ace
Taipei, Taiwan, Republic of Taiwan: IOSH, 1992.

21 Veulemans H, Groeseneken D, Masschelein R, et al. Field study of the urinary excretion of ethoxy acetic acid during study of the urinary excretion of ethoxy acetic acid during
repeated daily exposure to the ethyl ether of ethylene glycol repeated daily exposure to the ethyl ether of ethylene glycol
and ethyl ether of ethylene glycol acetate. Scand F Work
Environ Health 1987;13:239-42. 